\title{
The two-interacting compartmental (TIC) model of the rate of passage for herbivores: application to sheep digesta
}

\author{
C Corino 2, L Bernard 1, F Fontana 2, N Miraglia 2, P Zanetti 2 \\ 1 INRA, Laboratoire Dynamique de la Digestion, Theix, 63122 Saint-Genès-Champanelle, France \\ 2 Università degli Studi del Molise/Dept SAVA, Via Cavour, 50, Campobasso, Italy
}

The description of digesta passage in herbivores is a quite hard task if one takes into account the different physiological characteristics of the intestinal tract in different species. In the case of ruminants evidence exists that 2 compartmental models gave satisfactory results (ie Grovum and Williams, 1973). Unfortunately, the crude extension to other species of herbivores of the approaches presented up to now does not lead to statistically reliable results. Bearing this in mind, in previous papers (Corino et al, 1992), we presented a 2-interacting compartmental model (TIC model) devised to fit, in the most reliable way, experimental data on horses. The most important difference between the TIC model and those reported in the literature is that the 2 compartments that are assumed to mainly influence the digesta passage interact via a feedback mechanism. The TIC model is described by the following equations:

$$
y(t)=\frac{y_{1}(t)}{1+y_{1}(t)-y_{2}(t)}
$$

where $y(t)$ represent the cumulative amount of the marker normalized to $1, y_{1}(t)$ and $y_{2}(t)$ are:

$$
y_{1}(t)=1-e^{\frac{t-t_{0}}{k_{1}}} \quad y_{2}(t)=1-e^{\frac{t-t_{0}}{k_{2}}}
$$

where $t_{0}, k_{1}$ and $k_{2}$ are the parameters to be determined. The good reliability of this model prompted us to test it with other kind of herbi- vores, particularly ruminants. We tested the model on the experimental data obtained from 4 mature Texel wethers at the INRA of Theix; these animals received a ration constituted of different ratios of chopped (marker: Thulium) and ground (marker: Ytterbium) orchard-grass hay (Bernard et al, 1992). The application to the experimental data obtained from sheep gave satisfactory results and good fitting parameters. There are some general remarks on our results: 1) our model has a quite good level of statistical accuracy (the application of the ordinary chi-squared test returned a confidence level above $90 \%$ in any case); 2 ) relationships between physiological characteristics and the rate constants appear; and 3 ) the numerical analysis of the values estimated for the 2 characteristic parameters $\left(k_{1}\right.$ and $\left.k_{2}\right)$ shows statistically meaningful differences depending on the kind of marker use. Otherwise, the diet, seems to be less influential on the estimate of such parameters. Further development of our work will be the comparison of the results of our model to those of the other models reported in the literature and the comparison of the rate constants obtained by our model with the results obtained by duodenal-canulated animals.

Grovum WL, Williams VJ (1973) Br J Nutr 30, 313-329

Corino C, Fontana F, Miraglia N, Zanetti P (1992) 1st Eur Conf Horse Nutr Hannover 3-4 September

Bernard L, Chaise JP, Poncet C (1993) Ann Zootech 42, 155 